\title{
$\beta$-elemene decreases cell invasion by upregulating E-cadherin expression in MCF-7 human breast cancer cells
}

\author{
XIAN ZHANG ${ }^{1,2}$, YANG ZHANG ${ }^{1}$ and YINGHUA LI ${ }^{1}$ \\ ${ }^{1}$ Department of Oncology, Second Affiliated Hospital of Dalian Medical University, Dalian 116023; \\ ${ }^{2}$ Research Institute of Integrated Traditional and Western Medicine of Dalian Medical University, Dalian 116044, P.R. China
}

Received March 11, 2013; Accepted May 3, 2013

DOI: $10.3892 /$ or.2013.2519

\begin{abstract}
Inactivation of E-cadherin results in cell migration and invasion, hence leading to cancer aggressiveness and metastasis. Downregulation of E-cadherin is closely correlated with a poor prognosis in invasive breast cancer. Thus, re-introducing E-cadherin is a novel strategy for cancer therapy. The aim of the present study was to determine the effects of the traditional Chinese medicine, $\beta$-elemene (ELE), on E-cadherin expression, cell migration and invasion in the breast cancer cell line MCF-7. MCF-7 cells were treated with 50 and $100 \mu \mathrm{g} / \mathrm{ml}$ ELE. E-cadherin mRNA was analyzed by reverse transcription-polymerase chain reaction. E-cadherin protein levels were determined by immunofluorescence and western blot assays. Cell motility was measured by a Transwell assay. ELE increased both the protein and mRNA levels of E-cadherin, accompanied by decreased cell migration and invasion. Further analysis demonstrated that ELE upregulated estrogen receptor- $\alpha(\mathrm{ER} \alpha)$ and metastasis-associated protein 3 (MTA3), and decreased the nuclear transcription factor Snail. In conclusion, our results demonstrate that ELE decreases cell migration and invasion by upregulating E-cadherin expression via controlling the ER $\alpha /$ MTA3/Snail signaling pathway.
\end{abstract}

\section{Introduction}

E-cadherin is a calcium-regulated homophilic cell-cell adhesion molecule and is expressed in most normal epithelial tissues but is downregulated in most types of cancer cells (1). The absence of E-cadherin causes the dedifferentiation and invasiveness of human cancers (2), indicating that E-cadherin is a tumor suppressor (3). Either gene mutation or loss of the wild-type allele leads to inactivation of E-cadherin $(3,4)$. Selective loss of E-cadherin is one of the hallmarks of invasive breast cancer phenotypes (5). Decreased levels of E-cadherin

Correspondence to: Professor Yang Zhang, Department of Oncology, Second Affiliated Hospital of Dalian Medical University, 467 Zhongshan Road, Dalian 116023, P.R. China

E-mail: dlzlzx001@yahoo.com.cn

Key words: $\beta$-elemene, E-cadherin, breast cancer, MCF-7, cell invasion have been related to the distant metastasis and poor prognosis of breast cancer $(6,7)$. Therefore, increasing the expression of functional E-cadherin is a novel cancer therapeutic strategy. However, the potential application of traditional Chinese medicine in inducing the expression of E-cadherin in breast cancers is largely unexplored.

Elemene (1-methyl-1-vinyl-2,4-diisopropenyl-cyclohexane) is an active anticancer component of the traditional Chinese medicine Curcuma wenyujin (8). The extract of elemene is a mixture of $\alpha$-, $\beta$ - and $\delta$-elemene, with $\beta$-elemene (ELE) as the main component, which accounts for $60-72 \%$ of the three isoforms (9). ELE has shown anticancer activities in the clinical treatment of leukemia and carcinomas of the brain, breast and liver (8,10-12). One formulation of ELE has been approved by the State Food and Drug Administration of China for the treatment of primary and secondary brain tumors.

ELE inhibits cell proliferation by inducing cell cycle arrest and apoptosis, thereby reducing the metastasis or tissue invasion of cancer cells $(8,13,14)$. We previously found that ELE upregulated estrogen receptor- $\alpha$ (ER $\alpha)$ mRNA by downregulating the Ras/MAPK signaling pathway in the tamoxifen (TAM)-resistant cell line MCF-7/TAM (15). As $\mathrm{ER} \alpha$ suppresses the expression of the nuclear transcription factor Snail, a negative transcription factor of E-cadherin gene expression $(16,17)$, it is intriguing to propose that ELE may increase the expression of E-cadherin via activating the re-expression of ER $\alpha$ and hence inhibiting the gene transcription of Snail. In the present study, we analyzed the levels of E-cadherin expression and cell motility capacity of MCF-7 cells following ELE treatment.

\section{Materials and methods}

Chemicals and antibodies. ELE (98\% purity) was purchased from Dalian Yuanda Pharmaceuticals (Liaoning, China). The primary antibodies against E-cadherin (ab1416), ER $\alpha$ (ab2746), metastasis-associated protein 3 (MTA3) (ab87275), Snail (ab53519) and $\beta$-actin were from Abcam (Cambridge, UK). The secondary horseradish peroxidase (HRP)-conjugated goat anti-mouse-IgG and anti-rabbit-IgG antibodies were from Santa Cruz Biotechnology, Inc. (Santa Cruz, CA, USA).

Cell line and drug treatment. The MCF-7 human breast cancer cell line was obtained from the Cell Bank of the Chinese 
Academy of Sciences (Shanghai, China) and propagated in Dulbecco's modified Eagle's medium (DMEM)/high glucose supplemented with $20 \%$ fetal bovine serum (FBS) and $1 \%$ penicillin/streptomycin (Gibco, Carlsbad, CA, USA). MCF-7 cells were cultured at $37^{\circ} \mathrm{C}$ in a humidified incubator (Heraeus, Germany) with $5 \% \mathrm{CO}_{2}$ and seeded at $2.5 \times 10^{5}$ cells $/ \mathrm{ml}$ in 6-well plates (Corning, Inc., Corning, NY, USA). The cells were divided into three treatment groups $(0,50$ and $100 \mu \mathrm{g} / \mathrm{ml}$ ELE), observed and examined after $24 \mathrm{~h}$.

Immunofluorescence assay. For E-cadherin staining, cells were plated on glass coverslips in 6-well plates and treated with ELE for $24 \mathrm{~h}$. The cells were washed in phosphate-buffered saline (PBS), fixed in 4\% paraformaldehyde solution containing $0.1 \%$ Triton $\mathrm{X}-100$ for $20 \mathrm{~min}$ at room temperature (RT), incubated in 5\% bovine serum albumin for $30 \mathrm{~min}$ at RT, and then treated with the anti-E-cadherin monoclonal antibody for $16 \mathrm{~h}$ at $4^{\circ} \mathrm{C}$. After being washed three times in PBS, cells were further incubated with $\mathrm{CY} 3$ conjugated goat anti-mouse IgG (Beyotime Biotechnology, Haimeng, China) for $1 \mathrm{~h}$ at RT. After three washes with PBS, the cells were analyzed using a fluorescence inverted microscope (IX71; Olympus, Japan). The cells were counterstained with Hoechst 33258 (Beyotime Biotechnology) to label the cell nuclei.

Western blot analysis. Cells were washed twice with ice-cold PBS and lysed in $1 \%$ Triton buffer [1\% Triton X-100, $50 \mathrm{mM}$ Tris-Cl (pH 7.4), $150 \mathrm{mM} \mathrm{NaCl}, 10 \mathrm{mM}$ EDTA, $100 \mathrm{mM}$ $\mathrm{NaF}, 1 \mathrm{mM} \mathrm{Na} \mathrm{VO}_{4}$ (Sigma, St. Louis, MO, USA), $1 \mathrm{mM}$ phenylmethanesulfonyl fluoride (PMSF) and $2 \mu \mathrm{g} / \mathrm{ml}$ aprotinin] on ice. Total proteins were quantified using the Lowry method. Proteins $(50 \mu \mathrm{g})$ were separated by sodium dodecyl sulfate-polyacrylamide gel electrophoresis and electrophoretically transferred to polyvinylidene fluoride (PVDF) membranes (Immobilon-P; Millipore, USA). The membranes were blocked with $5 \%$ bovine serum albumin (Sigma) at RT for $1 \mathrm{~h}$ and incubated overnight at $4^{\circ} \mathrm{C}$ with the following primary antibodies: E-cadherin $(1: 1,000), \mathrm{ER} \alpha$ $(1: 1,000)$, MTA3 $(1: 2,000)$ and $\beta$-actin $(1: 500)$. After washing with Tris-buffered saline with Tween-20 (TBST) buffer, the membranes were probed with HRP-conjugated secondary antibodies and developed with enhanced chemiluminescence reagent (Beyotime Biotechnology). To detect Snail, nuclear proteins were extracted with a nuclear extraction kit (Beyotime Biotechnology) and probed with the anti-Snail antibody $(1: 2,000)$. The images were analyzed by NIH ImageJ software.

Real-time RT-PCR. Total RNA was extracted by homogenization in $1 \mathrm{ml}$ of TRIzol reagent (Invitrogen, Carlsbad, CA, USA), followed by chloroform re-extraction and isopropanol precipitation. RT-PCR was performed in a final volume of $20 \mu \mathrm{l}$ containing $1.6 \mathrm{ml}$ of cDNA template, $1 \mathrm{ml}$ of primer $(10 \mathrm{mM})$ and $10 \mathrm{ml}$ of SYBR-Green Master Mix (Takara, Dalian, China). Primers used were 5'-TCCCATCAGCT GCCCAGAAA-3' (sense) and 5'-TGACTCCTGTGTTCCTG TTA-3' (antisense) for E-cadherin; 5'-GCACCGTCAAGG CTGAGAAC-3' (sense) and 5'-TGGTGAAGACGCCAGT GGA-3' (antisense) for human GAPDH. GAPDH was used as an endogenous housekeeping gene.

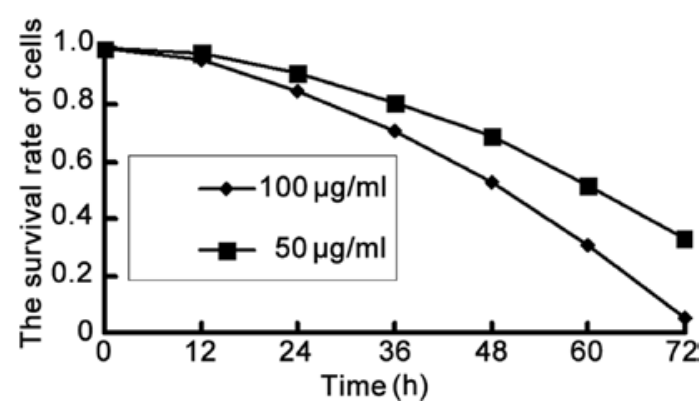

Figure 1. ELE inhibits the proliferation of MCF-7 cells. The absorbance values of MCF-7 cells treated with 50 and $100 \mu \mathrm{g} / \mathrm{ml}$ ELE for different times were read at $492 \mathrm{~nm}$ using a plate reader. The survival rate of cells was calculated based on the proliferation of MCF-7 cells when compared to the proliferation of the untreated group. ELE, $\beta$-elemene.

Transwell migration and invasion assay. Cell invasion was measured using a Transwell chamber. In brief, $2 \times 10^{5}$ cells were added per Transwell invasion chamber coated with $1-2 \mathrm{mg} / \mathrm{ml}$ Matrigel (reconstituted basement membrane; BD Biosciences, Mississauga, ON, Canada). MCF-7 cells were treated with ELE. Twenty-four hours later, the cells in the upper chamber were removed with a cotton swab. The remaining cells on the membrane were fixed for $10 \mathrm{~min}$ in methanol, stained with $1 \%$ crystal violet solution and washed with PBS. The number of invaded cells was counted for 5 fields/field of view at x200 magnification.

Cell viability assay. Cell viability was measured using the 3-(4,5-dimethylthiazol-2-yl)-2,5-diphenyltetrazolium bromide (MTT) assay. The cells were seeded at $5 \times 10^{4}$ cells/well in 96-well plates, incubated overnight and then exposed to the indicated concentrations of ELE for the indicated times. Next, $20 \mu 1$ of MTT (Sigma, St. Louis, MO, USA) solution $(5 \mathrm{mg} / \mathrm{ml}$ ) was added to each well, and the cells were incubated for another $4 \mathrm{~h}$ at $37^{\circ} \mathrm{C}$. After removal of the culture medium, the cells were lysed in $200 \mu 1$ of dimethyl sulfoxide (DMSO), and the optical density (OD) was measured at $570 \mathrm{~nm}$ with a microplate reader (Model 550; Bio-Rad Laboratories, USA). The following formula was used: Cell viability $=(\mathrm{OD}$ of the experimental sample/OD of the control group) $\mathrm{x} 100 \%$.

Statistical analysis. The experiments were repeated at least three times. Data are expressed as the means \pm standard deviation. Differences in the results between two groups were evaluated by the Student's t-test. $\mathrm{P}<0.05$ was considered to indicate a statistically significant result.

\section{Results}

Effect of ELE on the cell proliferation of MCF-7 cells. To examine the effect of ELE on the cell viability of MCF-7 cells, we treated the cells with 50 or $100 \mu \mathrm{g} / \mathrm{ml}$ ELE for $0,12,24,36$, 48,60 and $72 \mathrm{~h}$ and determined the rate of cell survival with an MTT assay. MCF-7 cell proliferation was not inhibited at 50 or $100 \mu \mathrm{g} / \mathrm{ml}$ ELE for $24 \mathrm{~h}(\mathrm{P}>0.05)$, whereas treatment of cells with both doses of ELE for $36 \mathrm{~h}$ significantly inhibited cell survival (Fig. 1) $(\mathrm{P}<0.05)$. Therefore, for our subsequent experiments, we treated cells with 50 and $100 \mu \mathrm{g} / \mathrm{ml} \mathrm{ELE} \mathrm{for}$ $24 \mathrm{~h}$, respectively. 


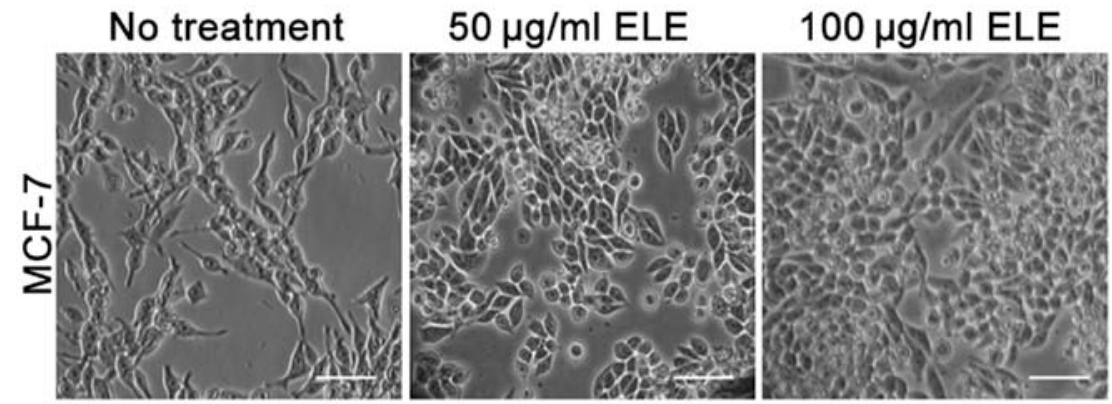

Figure 2. ELE induces phenotypic transition in MCF-7 cells. MCF-7 cells were cultured for three passages and seeded at $2.5 \times 10^{5}$ cells $/ \mathrm{ml}$ in 6-well plates. Cells from the three treatment groups were observed under an inverted microscope. (A) No treatment (control). (B and C) MCF-7 cells treated with 50 and $100 \mu \mathrm{g} / \mathrm{ml}$ ELE for $24 \mathrm{~h}$, respectively. Original magnification, x100. ELE, $\beta$-elemene.

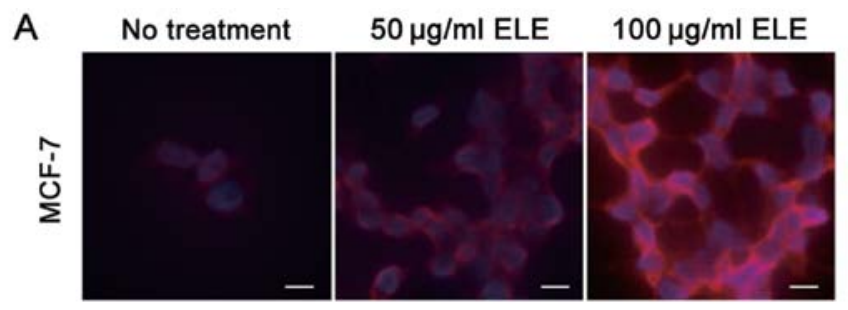

B

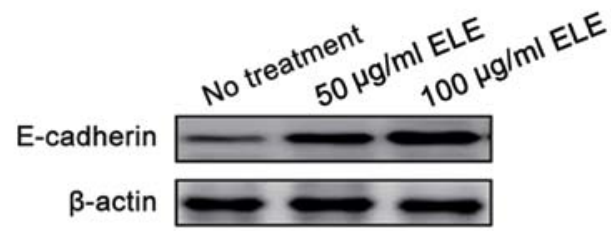

C

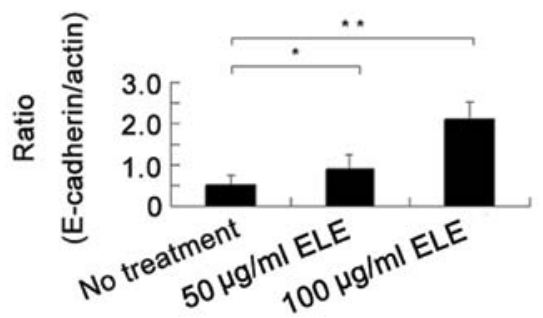

Figure 3. ELE increases E-cadherin protein levels. (A) MCF-7 cells were stained with E-cadherin antibody/secondary CY3 anti-mouse antibody (red). The cell nuclei were stained with Hoechst 33258 (blue). Cells of the three groups treated or not treated with ELE as above were observed and photographed using an inverted fluorescence microscope. Original magnification, $\mathrm{x}$ 400. (B) MCF-7 cells were analyzed for E-cadherin by western blotting (no treatment as control) after treatment with 50 and $100 \mu \mathrm{g} / \mathrm{ml} \mathrm{ELE}$. (C) Quantification of B. The columnar graph indicates that there was a significant difference between both treatment groups and the untreated control cells $\left({ }^{*} \mathrm{P}<0.05,{ }^{* *} \mathrm{P}<0.01\right)$. ELE, $\beta$-elemene.

ELE transforms the phenotype of MCF-7 cells. We used a microscope to approximately evaluate the cell motility capacity with the change in cell morphology of MCF-7 cells treated with 50 and $100 \mu \mathrm{g} / \mathrm{ml}$ ELE for $24 \mathrm{~h}$, respectively. ELE-treated cells demonstrated a loosely aggregated cell phenotype that switched gradually to a tight adherence, indicating increased cell-cell interactions and reduced capacity for motility (Fig. 2).

ELE increases the E-cadherin protein level in MCF-7 cells. To support the above-mentioned alteration in cell morphology,
A

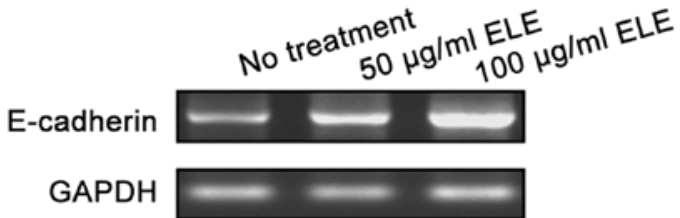

B

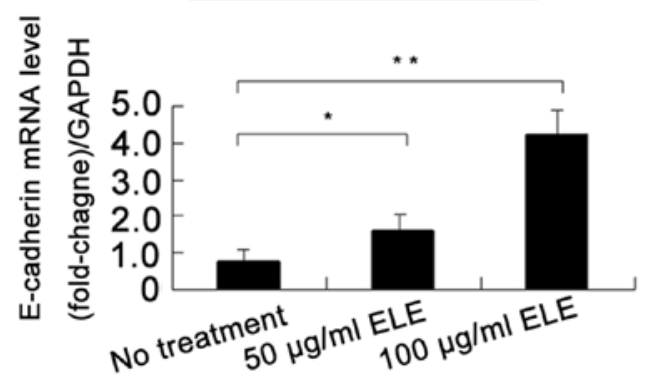

Figure 4. ELE upregulates E-cadherin mRNA levels. (A) The mRNA level of E-cadherin in MCF-7 cells treated with ELE was analyzed by RT-PCR. Following RT-PCR, the products were determined by agarose gel electrophoresis. (B) Quantification of A. The columnar graph indicates that there was a significant difference between both treatment groups and the untreated control cells $\left({ }^{*} \mathrm{P}<0.05,{ }^{* *} \mathrm{P}<0.01\right)$. ELE, $\beta$-elemene.

we next determined the E-cadherin protein levels in the MCF-7 cells by an immunofluorescence assay and found that E-cadherin protein was upregulated by ELE (Fig. 3A). Further western blot analysis showed that 50 and $100 \mu \mathrm{g} / \mathrm{ml} \mathrm{ELE}$ increased E-cadherin in a concentration-dependent manner (Fig. 3B and C) $(\mathrm{P}<0.05$ and $<0.01$, respectively). Thus, ELE upregulates E-cadherin protein levels.

ELE increases the E-cadherin $m R N A$ level in MCF-7 cells. To investigate whether ELE enhances the gene transcription of E-cadherin, we determined the E-cadherin mRNA levels in MCF-7 cells using an RT-PCR assay. ELE at 50 and $100 \mu \mathrm{g} / \mathrm{ml}$ significantly increased the mRNA levels of E-cadherin in a concentration-dependent manner (Fig. 4) $(\mathrm{P}<0.05$ and 0.01 , respectively), which was consistent with the upregulation of E-cadherin protein (Fig. 3). These results showed that ELE increased E-cadherin gene transcription.

ELE regulates $E$-cadherin expression via ER $/$ MTA3/Snail signaling. To determine the underlying mechanism by which ELE increases the expression of E-cadherin, we determined the protein levels of ER $\alpha$, MTA 3 and Snail. ELE at 50 and $100 \mu \mathrm{g} / \mathrm{ml}$ increased both ER $\alpha$ and MTA3, whereas it decreased 

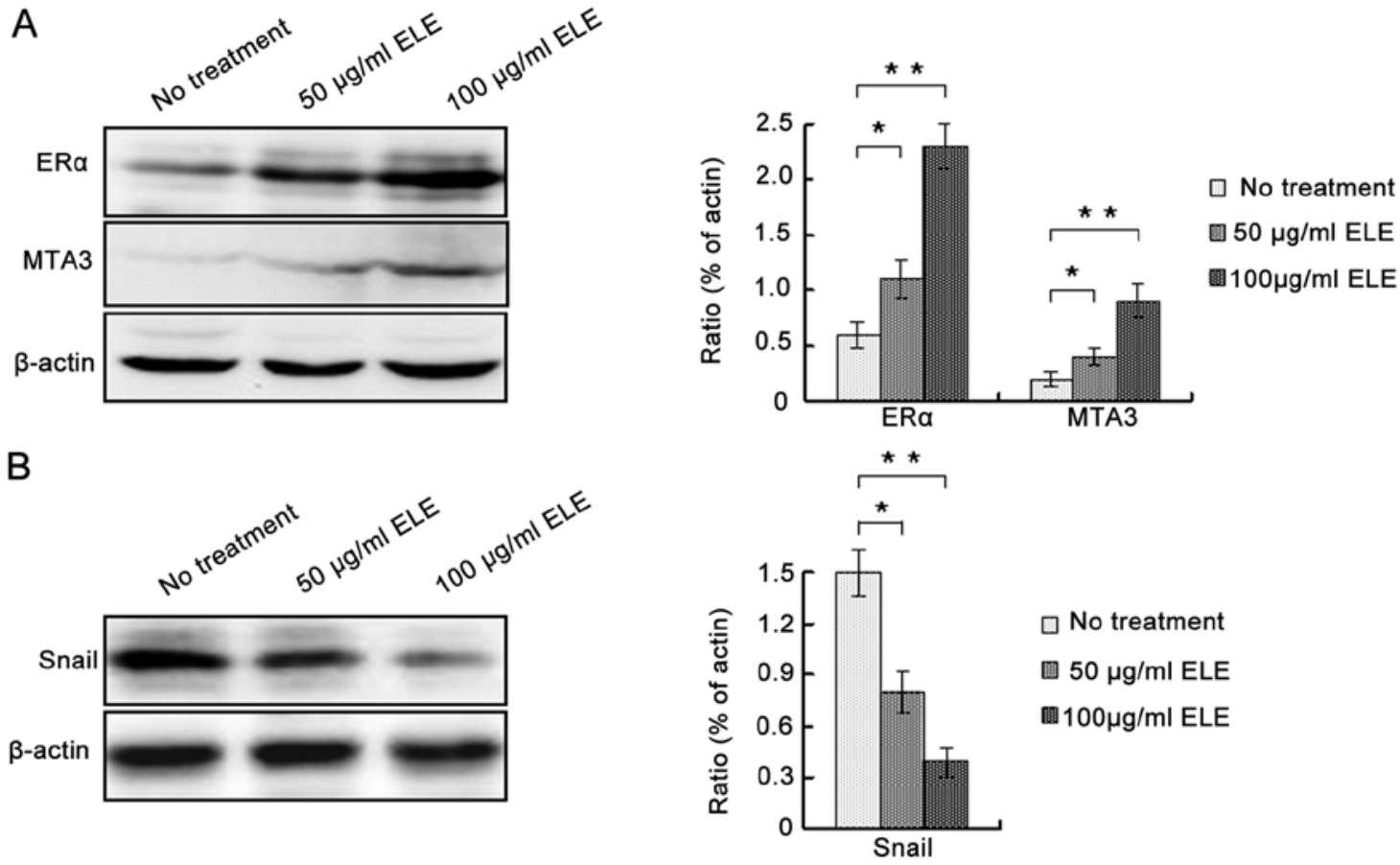

Figure 5. ELE alters the expression of ER $\alpha$, MTA3 and Snail. MCF-7 cells were treated with 50 and $100 \mu \mathrm{g} / \mathrm{ml}$ ELE and (A) ER $\alpha$ and MTA3 and (B) Snail were analyzed by western blot analyses. The right panels show the quantification of the corresponding western blots. The columnar graphs indicate that there was a significant difference between the two treatment groups and the control group $\left({ }^{*} \mathrm{P}<0.05,{ }^{* * *} \mathrm{P}<0.01\right)$. ELE, $\beta$-elemene.
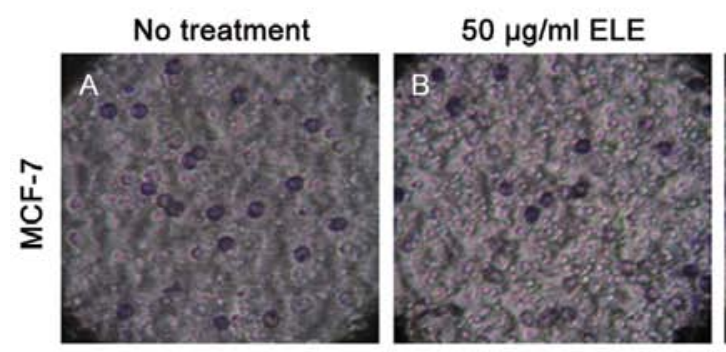

Migration
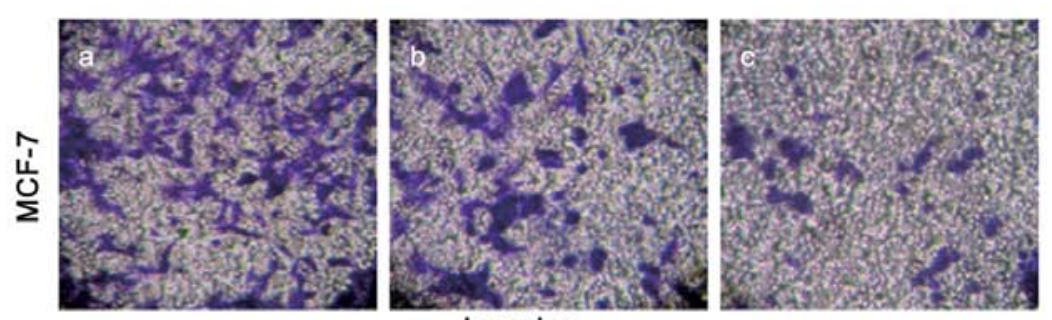

Invasion
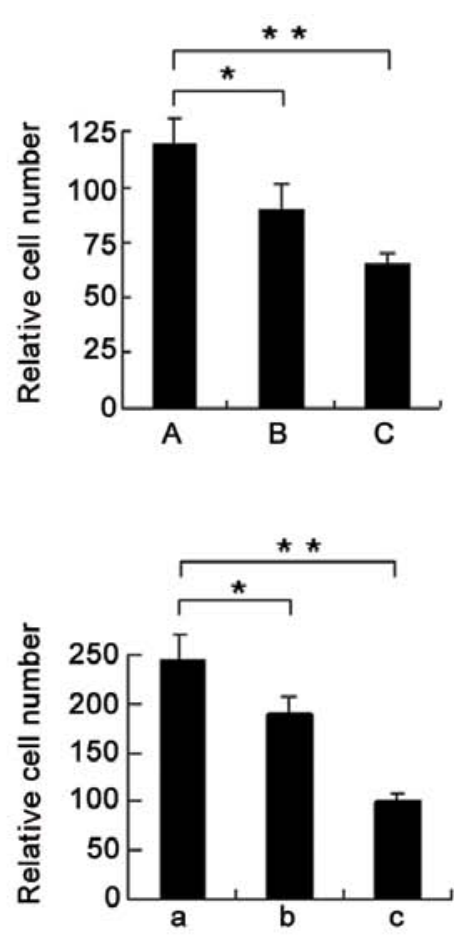

Figure 6. A Transwell assay assessed cell migration and invasion of MCF-7 cells. The invasiveness and migration of breast cancer cells were assessed using a Transwell migration and invasion assay. (A-C) The relative number of migrated MCF-7 cells following treatment with 0,50 and $100 \mu \mathrm{g} / \mathrm{ml}$ ELE; (a-c) the relative number of invasive MCF-7 cells in the three groups. Both migration (B and C) and invasion (b and c) were significantly decreased when compared to the negative control cells $\left({ }^{*} \mathrm{P}<0.05\right.$ and ${ }^{* *} \mathrm{P}<0.01$, respectively). Original magnification, $\mathrm{x} 200$. ELE, $\beta$-elemene.

Snail (Fig. 5A and B) $(\mathrm{P}<0.05$ and $<0.01$, respectively). In addition, increasing the concentration of ELE apparently enhanced these effects. Thus, ELE regulates E-cadherin expression via the ER $\alpha / \mathrm{MTA} 3 /$ Snail signaling pathway.
ELE affects the cell migration and invasion of MCF-7 cells. An increase in E-cadherin may explain the increased cellcell interactions and decreased capacity for motility of the MCF-7 cells following ELE treatment (Fig. 2). To further 
support this conclusion, we measured the cell migration and invasion of MCF-7 cells treated with ELE with a Transwell assay and found that cells successfully penetrated the basement membrane-coated chambers; however, the number of cells that penetrated the membrane was reduced significantly in the ELE-treated cells (Fig. 6) $(\mathrm{P}<0.05$ and $<0.01$, respectively, for the 50 and $100 \mu \mathrm{g} / \mathrm{ml}$ treatment groups). These data demonstrated that ELE inhibits both cell migration and invasion.

\section{Discussion}

E-cadherin is a cell adhesion molecule that is expressed in normal breast tissue, and decreased E-cadherin expression is correlated with the poor clinical prognosis of breast cancer. The status of the E-cadherin gene, including promoter methylation and mutation, is related to the capacity for cell motility of breast cancers (18). Loss of E-cadherin expression results in increased cellular motility, invasiveness, and resistance to apoptosis, which leads to epithelial-mesenchymal transition (EMT) $(19,20)$. Thus, reversing the functional protein levels of E-cadherin is an alternative strategy for cancer therapy. Reversing $\mathrm{CpG}$ hypermethylation in the promoter region of the E-cadherin gene could re-activate E-cadherin gene expression $(21,22)$. It has been proposed that targeting signal transduction pathways such as EGFR and ER may be a more promising method with which to restore E-cadherin levels (23-26).

In the present study, we discovered that ELE positively regulated the expression of E-cadherin in MCF-7 cells. Consistently, ELE induced a switch in cell morphology and reduced cell migration and invasion. Estrogen and its receptors regulate the expression of E-cadherin and EMT in breast cancer cells (27). The ER $\alpha$ maintains the epithelial morphology of breast cancer cells by activating $\mathrm{CDH}-1$, the E-cadherin encoding gene (28). It has been reported that ER signaling upregulates MTA3 levels to negatively modulate Snail-mediated repression of E-cadherin (29). Further studies have demonstrated that activation of the ER-MTA3-Snail-Ecadherin pathway in breast cancer is generally associated with a more favorable clinical outcome (30-33).

We previously found that ELE upregulates ER $\alpha$ mRNA and promotes the re-expression of ER $\alpha$ through downregulating the Ras/MAPK/ERK signaling pathway in MCF-7/TAM cells (15). In the present study, we showed that ELE increased ER $\alpha$ and MTA3, while reducing Snail. Thus, we demonstrated that ELE enhances the E-cadherin system and decreases the cell motility capacity by mediating the ER/ MTA3/Snail/E-cadherin pathway in the breast cancer cell line MCF-7. These results suggest that the traditional Chinese medicine $\beta$-elemene is a promising agent for the treatment of breast cancers.

\section{Acknowledgements}

We thank Luping Zheng (The Research Institute of Integrated Traditional and Western Medicine, Dalian Medical University) for the technical assistance. This study was approved by the Ethics Committee of the Second Affiliated Hospital of Dalian Medical University.

\section{References}

1. Hazan RB and Norton L: The epidermal growth factor receptor modulates the interaction of E-cadherin with the actin cytoskeleton. J Biol Chem 273: 9078-9084, 1998.

2. Cheng CW, Wu PE, Yu JC, et al: Mechanisms of inactivation of E-cadherin in breast carcinoma: modification of the two-hit hypothesis of tumor suppressor gene. Oncogene 20: 3814-3823, 2001.

3. Berx G, Cleton-Jansen AM, Nollet F, et al: E-cadherin is a tumour/invasion suppressor gene mutated in human lobular breast cancers. EMBO J 14: 6107-6115, 1995.

4. Vos CB, Cleton-Jansen AM, Berx G, et al: E-cadherin inactivation in lobular carcinoma in situ of the breast: an early event in tumorigenesis. Br J Cancer 76: 1131-1133, 1997.

5. Yoshida R, Kimura N, Harada Y and Ohuchi N: The loss of E-cadherin, $\alpha$ - and $\beta$-catenin expression is associated with metastasis and poor prognosis in invasive breast cancer. Int $\mathbf{J}$ Oncol 18: 513-520, 2001.

6. Parker C, Rampaul RS, Pinder SE, et al: E-cadherin as a prognostic indicator in primary breast cancer. $\mathrm{Br} \mathrm{J}$ Cancer 85: 1958-1963, 2001

7. Kowalski PJ, Rubin MA and Kleer CG: E-cadherin expression in primary carcinomas of the breast and its distant metastases. Breast Cancer Res 5: R217-R222, 2003.

8. Lu JJ, Dang YY, Huang M, et al: Anti-cancer properties of terpenoids isolated from Rhizoma Curcumae - a review. J Ethnopharmacol 143: 406-411, 2012.

9. Wang G, Li X, Huang F, et al: Antitumor effect of $\beta$-elemene in non-small-cell lung cancer cells is mediated via induction of cell cycle arrest and apoptotic cell death. Cell Mol Life Sci 62: 881-893, 2005.

10. Yao YQ, Ding X, Jia YC, et al: Anti-tumor effect of $\beta$-elemene in glioblastoma cells depends on p38 MAPK activation. Cancer Lett 264: 127-134, 2008.

11. Liu J, Zhang Y, Qu J, et al: $\beta$-Elemene-induced autophagy protects human gastric cancer cells from undergoing apoptosis. BMC Cancer 11: 183, 2011.

12. Li X, Wang G, Zhao J, et al: Antiproliferative effect of $\beta$-elemene in chemoresistant ovarian carcinoma cells is mediated through arrest of the cell cycle at the G2-M phase. Cell Mol Life Sci 62: 894-904, 2005.

13. Chen W, Lu Y, Wu J, et al: Beta-elemene inhibits melanoma growth and metastasis via suppressing vascular endothelial growth factor-mediated angiogenesis. Cancer Chemother Pharmacol 67: 799-808, 2011.

14. Yu Z, Wang R, Xu L, et al: $\beta$-Elemene piperazine derivatives induce apoptosis in human leukemia cells through downregulation of c-FLIP and generation of ROS. PLoS One 6: e15843, 2011.

15. Zhang B, Zhang X, Tang B, et al: Investigation of elemeneinduced reversal of tamoxifen resistance in MCF-7 cells through oestrogen receptor $\alpha(\mathrm{ER} \alpha)$ re-expression. Breast Cancer Res Treat 136: 399-406, 2012.

16. Oesterreich S, Deng W, Jiang S, et al: Estrogen-mediated downregulation of E-cadherin in breast cancer cells. Cancer Res 63: 5203-5208, 2003.

17. Scherbakov AM, Andreeva OE, Shatskaya VA and Krasil'nikov MA: The relationships between snaill and estrogen receptor signaling in breast cancer cells. J Cell Biochem 113: 2147-2155, 2012 .

18. van Horssen R, Hollestelle A, Rens JA, et al: E-cadherin promotor methylation and mutation are inversely related to motility capacity of breast cancer cells. Breast Cancer Res Treat 136: 365-377, 2012.

19. Foroni C, Broggini M, Generali D and Damia G: Epithelialmesenchymal transition and breast cancer: role, molecular mechanisms and clinical impact. Cancer Treat Rev 38: 689-697, 2012.

20. Korpal M,Lee ES, Hu G and Kang Y: The miR-200 family inhibits epithelial-mesenchymal transition and cancer cell migration by direct targeting of E-cadherin transcriptional repressors ZEB1 and ZEB2. J Biol Chem 283: 14910-14914, 2008.

21. Nam JS, Ino Y, Kanai Y, et al: 5-aza-2'-deoxycytidine restores the E-cadherin system in E-cadherin-silenced cancer cells and reduces cancer metastasis. Clin Exp Metastasis 21: 49-56, 2004.

22. Peng G, Wargovich MJ and Dixon DA: Anti-proliferative effects of green tea polyphenol EGCG on Ha-Ras-induced transformation of intestinal epithelial cells. Cancer Lett 238: 260-270, 2006. 
23. Lu Z, Ghosh S, Wang Z and Hunter T: Downregulation of caveolin-1 function by EGF leads to the loss of E-cadherin, increased transcriptional activity of beta-catenin, and enhanced tumor cell invasion. Cancer Cell 4: 499-515, 2003.

24. Mauro L, Pellegrino M, Lappano R, et al: E-cadherin mediates the aggregation of breast cancer cells induced by tamoxifen and epidermal growth factor. Breast Cancer Res Treat 121: 79-89, 2010.

25. Belguise K, Guo S and Sonenshein GE: Activation of FOXO3a by the green tea polyphenol epigallocatechin-3-gallate induces estrogen receptor $\alpha$ expression reversing invasive phenotype of breast cancer cells. Cancer Res 67: 5763-5770, 2007.

26. Helguero LA, Lindberg K, Gardmo C, et al: Different roles of estrogen receptors $\alpha$ and $\beta$ in the regulation of $E$-cadherin protein levels in a mouse mammary epithelial cell line. Cancer Res 68: 8695-8704, 2008

27. Planas-Silva MD and Waltz PK: Estrogen promotes reversible epithelial-to-mesenchymal-like transition and collective motility in MCF-7 breast cancer cells. J Steroid Biochem Mol Biol 104: 11-21, 2007.
28. Cardamone MD, Bardella C, Gutierrez A, et al: ER $\alpha$ as ligandindependent activator of $\mathrm{CDH}-1$ regulates determination and maintenance of epithelial morphology in breast cancer cells. Proc Natl Acad Sci USA 106: 7420-7425, 2009.

29. Kumar R: Another tie that binds the MTA family to breast cancer. Cell 113: 142-143, 2003.

30. Fujita N, Kajita M, Taysavang P and Wade PA: Hormonal regulation of metastasis-associated protein 3 transcription in breast cancer cells. Mol Endocrinol 18: 2937-2949, 2004.

31. Mishra SK, Talukder AH, Gururaj AE, et al: Upstream determinants of estrogen receptor- $\alpha$ regulation of metastatic tumor antigen 3 pathway. J Biol Chem 279: 32709-32715, 2004.

32. Yu JC, Hsu HM, Chen ST, et al: Breast cancer risk associated with genotypic polymorphism of the genes involved in the estrogen-receptor-signaling pathway: a multigenic study on cancer susceptibility. J Biomed Sci 13: 419-432, 2006.

33. Toh Y and Nicolson GL: The role of the MTA family and their encoded proteins in human cancers: molecular functions and clinical implications. Clin Exp Metastasis 26: 215-227, 2009. 